\title{
Therapeutic Analysis of Herbert Screw Fixation for Capitellar Fractures via the Anterior Approach in Children
}

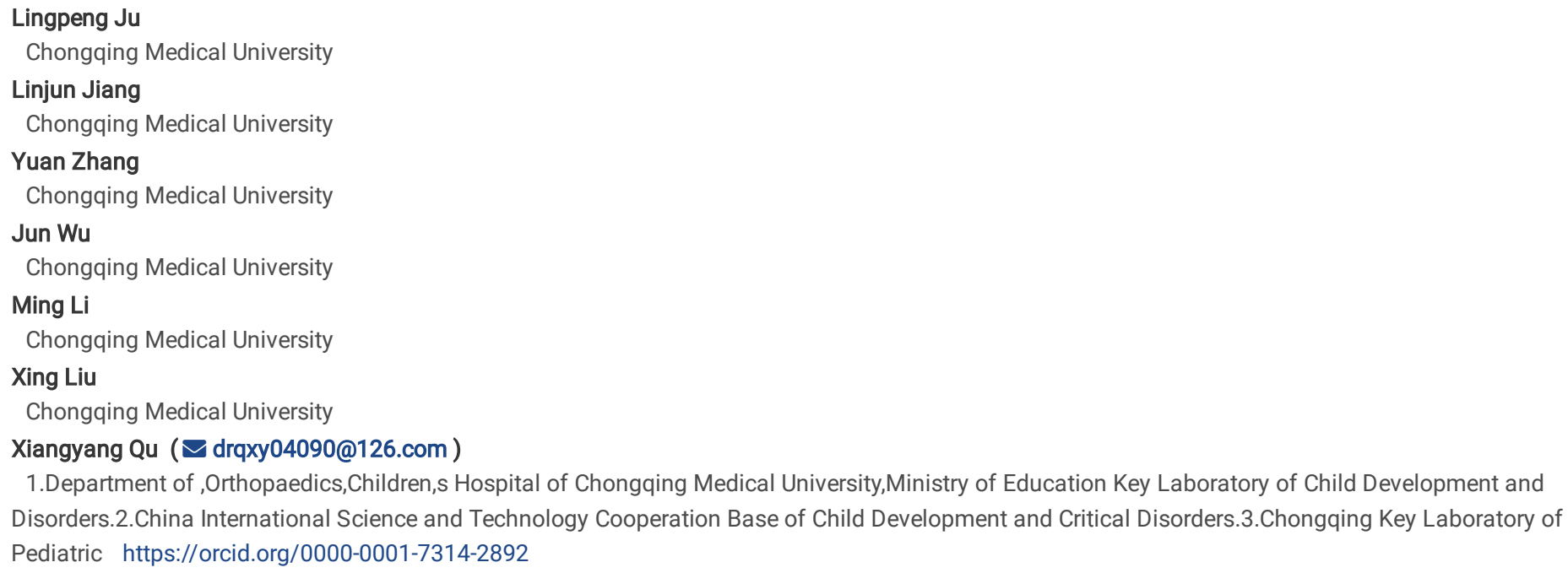




\section{Abstract}

Objective: To analyse the efficacy of open reduction and Herbert screw fixation for coronal fractures of the capitellum via the anterior approach in children.

Methods: We retrospectively analysed the clinical and imaging data of 15 children with capitellar fractures who were admitted to our hospital from May 2014 to May 2019. The fracture was reduced through the cubital crease incision via the anterior approach and was internally fixated with Herbert screws. A followup was conducted after the operation to examine the fracture healing and elbow function. The postoperative functional recovery of patients was evaluated with the Mayo Elbow Performance index (MEPI) and the Broberg-Morrey rating system.

Results: Patients underwent surgery 3.7 days after injury on average. Intraoperative fracture reduction was satisfactory. No vascular injury or nerve injury occurred. Bony union occurred in an average of 6 weeks after the operation. All children completed 12- to 36-month follow-up. At the last follow-up, the Mayo Elbow Performance index was considered excellent in 12 patients and good in three patients. The Broberg-Morrey score was considered excellent in 12 patients, good in two patients, and fair in one patient.

Conclusion: Open reduction and Herbert screw fixation via the anterior approach are an ideal surgical method for the treatment of coronal fractures of the capitellum in children.

Levels of Evidence: Therapeutic, retrospective study-Level IV

\section{Introduction}

Capitellar fracture in children is rare. Its incidence rate accounts for approximately $0.5-1 \%$ of elbow fractures in children $[1,2]$. Because the capitellum is located deep in the joint capsule, capitellar fracture in children typically does not cause apparent deformity in the elbow but manifests as swelling, pain, and dysfunction of the elbow joint. Anteroposterior or lateral radiography of the elbow joint cannot accurately diagnose all types of capitellar fractures. Therefore, the missed diagnosis and misdiagnosed rates of capitellar fractures in children are high [3]. Oblique radiography, computed tomography (CT), magnetic resonance imaging (MRI), and arthrography of the elbow joint are very important for the diagnosis of capitellar fracture in children [1,3,4].

Open reduction and internal fixation are the main approach to treat displaced capitellar fractures [1]. Capitellar fractures in children are intra-articular fractures. These fractures are prone to complications such as heterotopic ossification, avascular necrosis of bone, elbow stiffness, and posttraumatic arthritis [5]. It is very important to restore the anatomical structure of the articular surface to reduce the occurrence of posttraumatic arthritis [6]. The purpose of open reduction and internal fixation is to reconstruct the anatomical structure of the capitellum, restoring the smoothness and flatness of the articular surface and providing firm fixation to promote fracture healing and to restore elbow function.

To date, there is no unified opinion on the surgical approach and fixation selection for the treatment of capitellar fractures $[1,5,7,8]$. The lateral and posterior approach are the most commonly used surgical approaches for elbow joint surgery [9]. However, for the treatment of capitellar fractures, the lateral and posterior approaches provide poor exposure to the fracture, which hinders fracture reduction and internal fixation [10]. This article retrospectively analyses the clinical data of 15 children and explores the effects of open reduction through the anterior approach and Herbert screw fixation for the treatment of capitellar fractures in children.

\section{Patients And Methods}

Approval for the retrospective case series was granted by the Institutional Review Board of Children's Hospital of Chongqing Medical University. This study included 15 children with coronal fractures of the capitellum who were treated in our hospital from May 2014 to May 2019 . The inclusion criteria were as follows: 1) patients with complete medical record data; 2) patients with coronal fractures of the capitellum confirmed by CT and three-dimensional reconstruction of the affected elbow joint; 3) patients undergoing open reduction and Herbert screw fixation through transverse incision in the cubital crease via the anterior approach; and 4) patients who completed a follow-up of at least 12 months.

Under successful anaesthesia, a transverse incision was made at the cubital crease on the anterior aspect of the elbow (the midpoint of the incision was at the lateral $1 / 3$ of the cubital crease) to expose the fracture site via the intermuscular space, with protection of the radial nerves between the brachialis and brachioradialis. Under direct vision, reduction of the capitellum was performed. A Kirschner wire was used to temporarily fixate the fractured fragment. An Herbert screw was inserted over the Kirschner wire after C-arm fluoroscopy showed satisfactory reduction. Then, C-arm fluoroscopy was repeated to confirm the effectiveness of the reduction. The incision was closed with absorbable suture, and the affected limb was immobilized with a cast. The incision dressing was changed 2-3 days after surgery. One week after the operation, the cast was removed and replaced with an orthosis. Elbow function training started under the guidance of a physician.

Follow-up was performed every 2-3 weeks after surgery until the fracture line was blurred or disappeared and the elbow joint was painless during functional activities. After that, follow-up was performed every 2-3 months within one year after surgery and every six months afterwards. The degree of pain of the affected limb, daily activities and elbow function were examined and recorded. The elbow function was assessed according to the MEPI [11] and the BrobergMorrey rating system [12]. A MEPI score $\geq 90$ was considered excellent, $75-89$ good, $60-74$ fair, and $<60$ poor. The Broberg-Morrey score $\geq 95$ was considered excellent, $80-94$ good, $60-79$ fair, and $\leq 59$ poor.

\section{Results}


A total of 15 children were enrolled in this study, including 10 boys and 5 girls with an average age of 13.1 years at the time of surgery. Fractures were in the left elbow in six patients and in the right elbow in nine patients. The patients underwent surgery 1 to 9 days after injury (as shown in Table 1). All operations were performed by the same senior surgeon. The operative time was approximately 35-60 minutes. The blood loss was approximately 10-40 ml, and there was no vascular or nerve damage during the operation. After the operation, the sensation and motion of the children's fingers were normal.

Table 1

Patient information and functional outcomes

\begin{tabular}{|c|c|c|c|c|c|c|c|c|c|c|c|c|c|}
\hline $\begin{array}{l}\text { Patient } \\
\text { ID }\end{array}$ & Age & Sex & $\begin{array}{l}\text { Injured } \\
\text { sites }\end{array}$ & $\begin{array}{l}\text { Causes of } \\
\text { injury }\end{array}$ & $\begin{array}{l}\text { Time } \\
\text { from } \\
\text { injury } \\
\text { to } \\
\text { surgery }\end{array}$ & $\begin{array}{l}\text { Time for } \\
\text { final } \\
\text { follow- } \\
\text { up } \\
\text { (months) }\end{array}$ & $\begin{array}{l}\text { Extension } \\
\text { on the } \\
\text { affected } \\
\text { side }\end{array}$ & $\begin{array}{l}\text { Flexion } \\
\text { on the } \\
\text { affected } \\
\text { side }\end{array}$ & $\begin{array}{l}\text { Pronation } \\
\text { on the } \\
\text { affected } \\
\text { side }\end{array}$ & $\begin{array}{l}\text { Supination } \\
\text { on the } \\
\text { affected } \\
\text { side }\end{array}$ & $\begin{array}{l}\text { BM } \\
\text { score }\end{array}$ & MEPI & Complication؛ \\
\hline 1 & 13 & G & $\mathrm{L}$ & Fall & 3 & 12 & 0 & 135 & 90 & 90 & 100 & 100 & \\
\hline 2 & 13 & B & $\mathrm{R}$ & $\begin{array}{l}\text { Fall } \\
\text { during } \\
\text { running }\end{array}$ & 5 & 12 & 0 & 140 & 90 & 80 & 100 & 100 & \\
\hline 3 & 15 & B & $\mathrm{L}$ & $\begin{array}{l}\text { Fall } \\
\text { during a } \\
\text { basketball } \\
\text { game }\end{array}$ & 5 & 12 & -30 & 120 & 60 & 70 & 86 & 80 & $\begin{array}{l}\text { Elbow } \\
\text { dysfunction }\end{array}$ \\
\hline 4 & 12 & B & $\mathrm{L}$ & Fall & 9 & 15 & -20 & 130 & 70 & 80 & 90 & 85 & $\begin{array}{l}\text { Elbow } \\
\text { dysfunction }\end{array}$ \\
\hline 5 & 15 & B & $\mathrm{R}$ & $\begin{array}{l}\text { Fall } \\
\text { during } \\
\text { running }\end{array}$ & 1 & 15 & 0 & 140 & 80 & 80 & 100 & 100 & \\
\hline 6 & 11 & G & $\mathrm{R}$ & Fall & 3 & 15 & -20 & 100 & 60 & 50 & 75 & 85 & $\begin{array}{l}\text { Elbow } \\
\text { dysfunction }\end{array}$ \\
\hline 7 & 14 & G & $\mathrm{L}$ & Fall & 3 & 17 & 0 & 140 & 70 & 90 & 100 & 100 & \\
\hline 8 & 13 & B & $\mathrm{R}$ & Fall & 3 & 18 & 0 & 140 & 90 & 90 & 100 & 100 & \\
\hline 9 & 13 & B & $\mathrm{L}$ & Fall & 3 & 18 & 0 & 135 & 90 & 80 & 100 & 100 & \\
\hline 10 & 13 & B & $\mathrm{R}$ & $\begin{array}{l}\text { Fall } \\
\text { during } \\
\text { running }\end{array}$ & 4 & 19 & -5 & 135 & 80 & 90 & 99 & 100 & \\
\hline 11 & 12 & B & $\mathrm{R}$ & Fall & 2 & 23 & 0 & 135 & 90 & 90 & 100 & 100 & \\
\hline 12 & 13 & B & $\mathrm{R}$ & Fall & 3 & 24 & 0 & 130 & 90 & 90 & 99 & 100 & Incision scar \\
\hline 13 & 14 & B & $\mathrm{L}$ & $\begin{array}{l}\text { Fall } \\
\text { during } \\
\text { running }\end{array}$ & 4 & 26 & -5 & 140 & 90 & 90 & 100 & 100 & \\
\hline 14 & 14 & G & $\mathrm{R}$ & $\begin{array}{l}\text { Fall from } \\
\text { a bicycle }\end{array}$ & 4 & 27 & 0 & 140 & 90 & 90 & 100 & 100 & \\
\hline 15 & 12 & G & $\mathrm{R}$ & Fall & 4 & 36 & 0 & 135 & 80 & 80 & 100 & 100 & \\
\hline
\end{tabular}

The patients were followed up for an average of 19.2 months (12-36 months). There were no signs of infection, such as redness, swelling, or exudation, at the incision after surgery. The incision had healed by the outpatient follow-up 2-3 weeks after the operation. One child had an incision scar. The fracture healing time was 4-7 weeks ( 6 weeks on average). There was no delayed union or nonunion of the fracture.

At the last follow-up, the internal fixation was stable, and no breakage and loosening of screws, infection, posttraumatic arthritis, or other complications were reported. The average ranges of extension, flexion, pronation, and supination of the affected elbow joint were $-5.3^{\circ}\left(\right.$ range: $\left.-30-0^{\circ}\right), 133^{\circ}\left(\right.$ range: $\left.100-140^{\circ}\right)$, $81.3^{\circ}$ (range: $60-90^{\circ}$ ), and $82.7^{\circ}$ (range: $50-90^{\circ}$ ), respectively (as shown in Table 1). The mean MEPI score was 96.7 points (range $80-100$ points). The MEPI scores indicated excellent efficacy in 12 patients and good in three patients. The mean Broberg-Morrey score was 96.6 points (range 75-100 points). By this score, the efficacy was excellent in 12 patients, good in two patients, and fair in one patient. A typical case is shown in Fig. 1.

A total of three patients developed elbow dysfunction after surgery. Case 1 (patients 4) was a missed diagnosis by another hospital. The patient was diagnosed with capitellar fracture via CT in our hospital one week after the injury and received surgery on the 9th day after the injury. After the cast was removed on the 6th day after operation, the patient started functional exercise. At the last follow-up 12 months after surgery, the patient had a range of elbow motion of $20-130^{\circ}$. Case 2 (patients 6 ) was an 11-year-old girl who did not follow the doctor's instructions for functional exercise due to the fear of pain. At the last follow-up 15 months after the operation, radiographs indicated that the fracture had healed well, but the range of elbow motion was limited, with the ranges of flexion and extension of $20-100^{\circ}$. Case 3 (patients 3 ) was a 15 -year-old boy. He was followed up by another hospital after the operation. The affected elbow was immobilized with a cast, and he did not perform functional exercise. At the 4th week after the operation, he was evaluated in the outpatient clinic of our hospital for the first time and started functional training. The patient started elbow functional exercises (physical therapy) in the 
department of rehabilitation of our hospital after the flexion contracture of his elbow joint was approximately $40^{\circ} 4$ months after the operation. The range of flexion and extension of his elbow joint reached $30-120^{\circ}$ at the last follow-up 15 months after surgery.

\section{Discussion}

Capitellar fractures in children are more common among adolescents than other age groups, which is related to the development of the anatomical structure of the elbow joint $[8,13]$. In young children, there are anatomical and mechanical weak areas at the junction of the humeral condyle and the humeral shaft

[14]. Violence often leads to humeral supracondylar fractures. In addition, nonossified secondary ossification centres in children's elbow joints, which starts to fuse around the age of 12 years [15]囚provide a cushioning effect against external stress. Therefore, capitulum fractures often occur in older children. The ossification centre of the capitellum has an anterior inclination of approximately $40^{\circ}$, resulting in an angle of approximately $140^{\circ}$ between it and the humeral shaft [16]. Capitellar fracture is often considered to be the result of the shear force on the capitellum caused by the direct impact of the radial head on the capitellum $[17,18]$. So coronal fractures of the capitellum are the most common type.

There are still controversies about the surgical approach for capitellar fractures. Many researchers have utilized the lateral or posterior approach in their studies $[1,5,8]$. Ravishankar et al [19] suggests that the lateral approach may cause the laxity of the lateral collateral ligament, and the repair of the ligament during the operation will prolong the operation time. Ballesteros et al [10] suggests that due to the lack of operating space when using the lateral approach, the screw cannot be implanted perpendicularly to the fracture surface, which affects the fixation effect. The posterior approach may damage the blood supply to the posterior capitellum $[20,21]$. The anterior approach can provide sufficient exposure of the fractured fragments and has gradually become the preferred surgical approach for open reduction of supracondylar fractures of the humerus in children [22]. However, some researchers argue that this approach may damage blood vessels and nerves [23]. In this study, capitellar fractures were reduced and fixed via the anterior approach. There was no vessel or nerve damage during the operation. Since the median nerve, ulnar nerve, and brachial vessels are medial to the elbow joint, damage to the main blood vessels and nerves can be avoided with slight retraction of the superficial elbow vein and cutaneous nerve after incision and protection of the radial nerves between the brachialis and brachioradialis..

Moreover, due to the non-fully developed muscles of the anterior elbow in children, the fracture site can be quickly and clearly exposed by gentle retraction of muscles during the operation, and the fracture can be reduced and fixated under direct vision. In addition, because the incision is made along the cubital crease of the elbow, which was consistent with the skin pattern of the elbow joint, the application of intradermal suture is conductive to incision healing and an aesthetic outcome. Only one patient had an incision scar in this study. The results of this study show that the anterior approach is safe for the surgical operation of capitellar fractures in children. It can sufficiently expose the operative field to allow the surgeon to perform fracture reduction under direct vision.

Choosing an appropriate internal fixator is key to the treatment of capitellar fractures. Kirschner wire is the most commonly used fixator for fractures in children, but it has certain limitations for the treatment of capitellar fractures. The Kirschner wire passes through the articular surface but cannot provide stable fixation of the fractured fragments, and long-term cast immobilization after the operation is needed. This cannot meet the requirements of early elbow movement and is prone to cause elbow stiffness [24]. Some researchers choose absorbable screws to fixate capitellar fractures in children, but their absorbability makes the strength of such screws uncertain. Compared with metal internal fixators, absorbable screws may extend the time needed for external fixation [9]. Capitellar fractures are intra-articular fractures, and long-term external fixation is not conducive to the recovery of elbow function. Moreover, an absorbable material may cause serious complications such as foreign body reactions, and there is a potential risk for stunted development of the epiphysis in children [25].

In this study, Herbert screws were used to fixate capitellar fractures. Elkowitz et al [26] suggest that headless screws provide better stability than cancellous bone screws. For treatment of intra-articular fractures, anatomical reduction and firm fixation of the fracture are key to fracture healing and functional recovery [27]. Since the Herbert screw is completely driven into the articular cartilage, it will not affect the smoothness or integrity of the articular surface and has almost no effect on joint movement. Herbert screws can provide a firm fixation of fracture fragments, and patients can start functional exercise early after surgery. This can effectively prevent postoperative complications such as elbow stiffness.

Three children in this study had elbow dysfunction. One of them had a missed diagnosis in another hospital and was later diagnosed with capitellar fracture by CT examination in our hospital. Due to the long time from injury to surgery, the child still had a certain degree of elbow dysfunction even after functional exercises. The other two children developed postoperative elbow dysfunction due to nonadherence to functional exercises. The function of the elbow joint in the other children had recovered well at the last follow-up. We should be watchful of capitellar fractures in adolescents with elbow joint injuries. CT, MRI, or arthrography can be used to confirm the diagnosis. For those with surgical indications, surgery should be performed as soon as possible, and effective functional exercises should be carried out promptly after the operation. These measures can effectively prevent postoperative elbow dysfunction.

The limitations of this study include that it was a retrospective analysis and that it lacked a randomized controlled design. As capitellar fractures are rare, the sample was small, and long-term follow-up was not performed. Future research should include a multicentre, randomized, controlled study to further investigate the effectiveness (and its correlates) of open reduction through the anterior approach and the use of Herbert screws in the treatment of capitellar fractures in children.

\section{Conclusion}

In this study, open reduction through the anterior approach and Herbert screw fixation were used to treat coronal fractures of the capitellum in children. The results of the study show that the anterior approach is safe for the surgical repair of capitellar fractures in children. It can sufficiently expose the operative field for the surgeon to perform fracture reduction under direct vision. Herbert screw fixation can provide reliable fixation without damaging the flatness of the 
articular surface. Open reduction via the anterior approach and Herbert screw fixation are an ideal surgical method for the treatment of coronal fractures of the capitellum in children.

\section{Abbreviations}

MEPI: the Mayo Elbow Performance index

CT: computed tomography

MRI: magnetic resonance imaging

\section{Declarations}

Ethics approval:

Approval was granted by the Institutional Review Board of Children's Hospital of Chongqing Medical University.

\section{Consent to publish:}

The subject shown in Fig.1 and her parents signed informed consent regarding publishing their data and photographs.

\section{Availability of data and materials:}

The datasets used and analysed during the current study are available from the corresponding author on reasonable request.

\section{Conflicts of interest:}

The authors declare that they have no competing interests.

\section{Funding:}

This research did not receive any specific grant from funding agencies in the public, commercial, or not-for-profit sectors.

\section{Authors' contributions:}

Xiangyang Qu designed the study. Yuan Zhang and Lingpeng Ju selected the appropriate patients and included them in this study. Lingpeng Ju, Yuan Zhang, Ming Li, Xing Liu and Xiangyang Qu collected the data and performed the statistical analysis.Lingpeng Ju and Linjun Jiang drafted the manuscript. Jun Wu, and Xiangyang Qu critically revised the manuscript.

\section{Acknowledgements:}

We thank all of the patients involved in the study. We thank the Department of Radiology of the Children's Hospital of Chongqing Medical University for providing X-ray images.

\section{References}

1. Murthy PG, Vuillermin C, Naqvi MN, et al. Capitellar Fractures in Children and Adolescents: Classification and Early Results of Treatment. J Bone Joint Surg Am. 2017;99:1282-90. https://doi.org/10.2106/JBJS.16.01393.

2. Papamerkouriou YM, Tsoumpos P, Tagaris G, et al. Type IV capitellum fractures in children. BMJ Case Rep. 2019;12. https://doi.org/10.1136/bcr-2019229957.

3. Frank JM, Saltzman BM, Garbis N, et al. Articular shear injuries of the capitellum in adolescents. J Shoulder Elbow Surg. 2016;25:1485-90. https://doi.org/10.1016/j.jse.2016.03.013.

4. Pradhan BB, Bhasin D, Krom W. Capitellar fracture in a child: the value of an oblique radiograph. A case report. J Bone Joint Surg Am. 2005;87:635-8. https://doi.org/10.2106/JBJS.B.2887pp.

5. Onay T, Gümüştaş SA, Baykan SE, et al. Mid-term and Long-term Functional and Radiographic Results of 13 Surgically Treated Adolescent Capitellum Fractures. J Pediatr Orthop. 2018;38:e424-424e428. https://doi.org/10.1097/BP0.0000000000001208.

6. Chang-Wug Oh. Articular fractures: principles. In: Buckley, Richard E, Moran, Christopher G, Theerachai Apivatthakakul, editor. AO Principles of Fracture Management, 3rd ed. Switzerland Davos Platz; 2018. p. 93-104.

7. Sułko J, Oberc A. Capitellar fractures in children. Ortop Traumatol Rehabil. 2014;16:573-9. https://doi.org/10.5604/15093492.1135047.

8. Kurtulmus T, Saglam N, Saka G, et al. Posterior fixation of type IV humeral capitellum fractures with fully threaded screws in adolescents. Eur J Trauma Emerg Surg. 2014;40:379-85. https://doi.org/10.1007/s00068-013-0332-0.

9. Cornelius AL, Bowen TR, Mirenda WM. Anterolateral approach for an unusual pediatric capitellar fracture: a case report and review of the literature. lowa Orthop J. 2012;32:215-9. 
10. Ballesteros-Betancourt JR, García-Tarriño R, García-Elvira R, et al. The anterior limited approach of the elbow for the treatment of capitellum and trochlea fractures: Surgical technique and clinical experience in eight cases. Injury. 2020;51 Suppl 1:S103-103S111. https://doi.org/10.1016/j.injury.2020.02.008.

11. Morrey BF, Bryan RS, Dobyns JH, et al. Total elbow arthroplasty. A five-year experience at the Mayo Clinic. J Bone Joint Surg Am. 1981;63:1050-63.

12. Broberg MA, Morrey BF. Results of delayed excision of the radial head after fracture. J Bone Joint Surg Am. 1986;68:669-74.

13. Fuad M, Elmhiregh A, Motazedian A, et al. Capitellar fracture with bony avulsion of the lateral collateral ligament in a child: Case report. Int $\mathrm{J}$ Surg Case Rep. 2017;36:103-7. https://doi.org/10.1016/j.ijscr.2017.04.026.

14. Vaquero-Picado A, González-Morán G, Moraleda L. Management of supracondylar fractures of the humerus in children. EFORT Open Rev. 2018;3:526-40. https://doi.org/10.1302/2058-5241.3.170049.

15. David L. Skaggs, Steven Frick. Upper Extremity Fractures in Children. In: Stuart L. Weinstein, John M. Flynn, editor. Lovell and Winter's Pediatric Orthopaedics, 7th ed. New York: Baltimore; 2017. p. 1708.

16. De Boeck H, Pouliart N. Fractures of the capitellum humeri in adolescents. Int Orthop. 2000;24:246-8. https://doi.org/10.1007/s002640000160.

17. Jeffrey R. Sawyer, James H. Beaty. Lateral Condylar and Capitellar Fractures of the Distal Humerus. In: John M. Flynn, David L. Skaggs, Peter M. Waters, editor. Rockwood and Wilkin's fractures in children, 8th Edition. New York: Baltimore; 2015. p. 721-723.

18. Mehdian H, McKee MD. Fractures of capitellum and trochlea. Orthop Clin North Am. 2000;31:115-27. https://doi.org/10.1016/s0030-5898(05)70132-2.

19. Ravishankar MR, Kumar MN, Raut R. Choice of surgical approach for capitellar fractures based on pathoanatomy of fractures: outcomes of surgical management. Eur J Orthop Surg Traumatol. 2017;27:233-42. https://doi.org/10.1007/s00590-016-1877-5.

20. Yamaguchi K, Sweet FA, Bindra R, et al. The extraosseous and intraosseous arterial anatomy of the adult elbow. J Bone Joint Surg Am. 1997;79:1653-62. https://doi.org/10.2106/00004623-199711000-00007.

21. Vaishya R, Vijay V, Jha GK, et al. Open reduction and internal fixation of capitellar fracture through anterolateral approach with headless double-threaded compression screws: a series of 16 patients. J Shoulder Elbow Surg. 2016;25:1182-8. https://doi.org/10.1016/j.jse.2016.01.034.

22. Wingfield JJ, Ho CA, Abzug JM, et al. Open Reduction Techniques for Supracondylar Humerus Fractures in Children. J Am Acad Orthop Surg. 2015;23:e7280. https://doi.org/10.5435/JAAOS-D-15-00295.

23. Yu T, Tao H, Xu F, et al. Comparison of lateral approach versus anterolateral approach with Herbert screw fixation for isolated coronal shear fractures of humeral capitellum. J Orthop Surg Res. 2019;14:230. https://doi.org/10.1186/s13018-019-1261-3.

24. Poynton AR, Kelly IP, O'Rourke SK. Fractures of the capitellum-a comparison of two fixation methods. Injury. 1998;29:341-3. https://doi.org/10.1016/s0020-1383(97)00107-1.

25. Böstman OM, Pihlajamäki HK. Adverse tissue reactions to bioabsorbable fixation devices. Clin Orthop Relat Res. 2000:216-27.

26. Elkowitz SJ, Polatsch DB, Egol KA, et al. Capitellum fractures: a biomechanical evaluation of three fixation methods. J Orthop Trauma. 2002;16:503-6. https://doi.org/10.1097/00005131-200208000-00009.

27. Kraus R. The pediatric vs. the adolescent elbow. Some insight into age-specific treatment. Eur J Trauma Emerg Surg. 2014;40:15-22. https://doi.org/10.1007/s00068-013-0342-y.

\section{Figures}



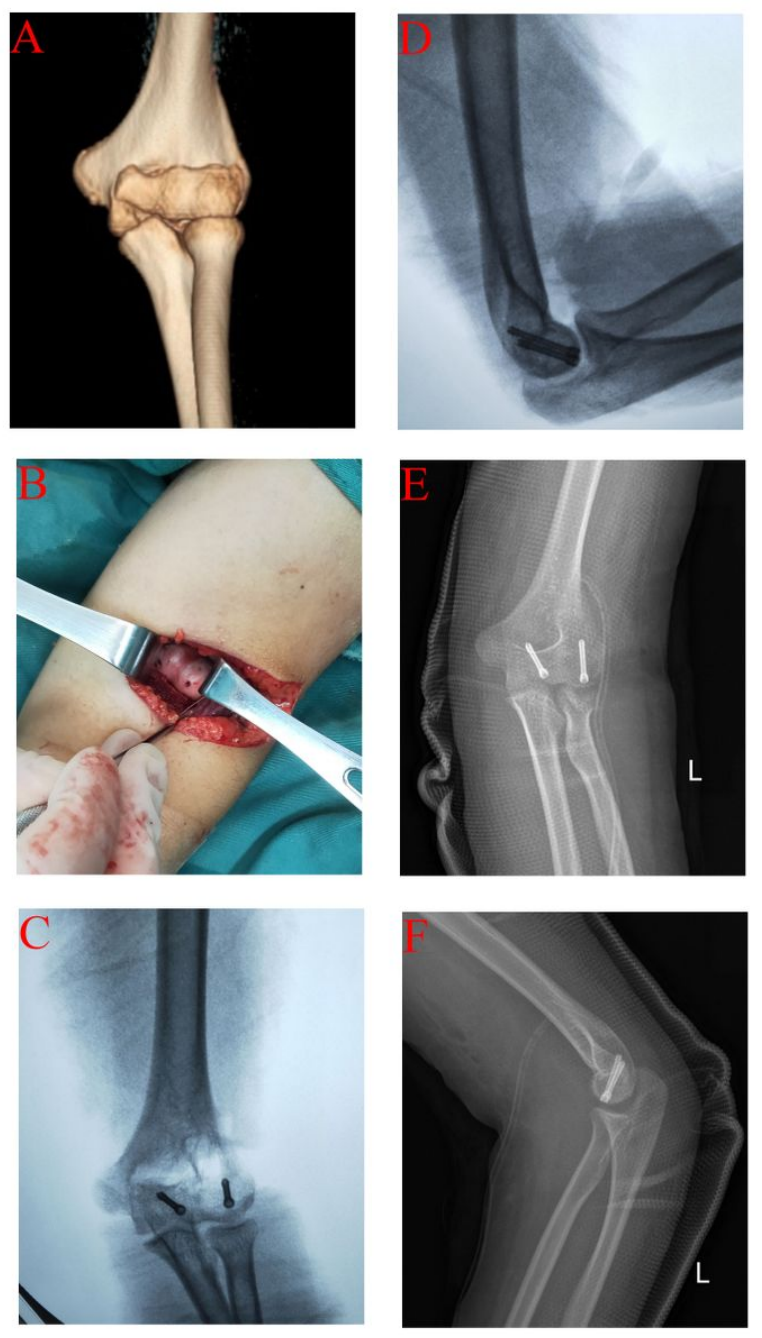

\section{Figure 1}

A 13-year-old girl presented with swelling, pain, and dysfunction of the left upper limb due to a fall. CT of the elbow joint showed a capitellar fracture (A). She underwent reduction of the capitellar fracture via the anterior approach under direct vision. Herbert screws were used to fixate the fracture fragments (B). Carm fluoroscopy (C: anteroposterior view of the elbow joint; D: lateral view of the elbow joint) confirmed satisfactory reduction and fixation of the fractures. Follow-up radiography was performed on the first day after surgery. The anteroposterior view $(\mathrm{E})$ and lateral view $(\mathrm{F})$ showed that the reduction and fixation were good. 